\title{
As medidas de confiança no Conselho de Defesa Sul-americano (CDS): análise dos gastos em Defesa (2009-2012)
}

\author{
The South American Defense Council (SDC) confidence \\ measures: a Defense expenditures analysis (2009-2012)
}

http://dx.doi.org/10.1590/0034-7329201400102

HÉCTOR LUIS SAINT-PIERRE*

ALBERTO MONTOYA CORREA PALACIOS JUNIOR**

Rev. Bras. Polít. Int. 57 (1): 22-39 [2014]

\section{Introdução}

As crises de segurança regional tornaram evidentes, para a percepção dos governos de América do Sul, a morosidade e a impotência dos foros hemisféricos para enfrentar seus problemas de segurança. Isso os levou a procurar novos caminhos para resolver essas questões, caminhos que não dependessem de atores extrarregionais. Como resultado, as questóes de Defesa assumiram prioridade nos processos de integração, surpreendendo analistas, contestando explicações e estremecendo teorias. ${ }^{1}$ Essas questôes prementes na região talvez expliquem o realce que o tema da Defesa recuperou nas Relações Internacionais com foco na América do Sul na última década, culminando na criação do Conselho Sul-americano de Defesa (CDS). Aqui pretendemos esclarecer os fundamentos, os objetivos e as inovações da transparência e as medidas de confiança na área da Defesa, assim como avaliar os resultados parciais da sua aplicação, porque consideramos que constituem os principais vetores integrativos no âmbito do CDS. Para isso, a) descrevemos o panorama dos processos interamericanos de medidas de confiança das Conferências de Ministros de Defesa das Américas (CMDA); b) avaliamos as relaçôes Argentina-Chile concomitantemente à construção da metodologia da

\footnotetext{
* Universidade Estadual Paulista (UNESP), Franca, SP, Brasil (hector.sp@uol.com.br).

** Universidade Estadual Paulista (UNESP), Franca, SP, Brasil (moontoya@gmail.com).

$1 \mathrm{O}$ ex-ministro José Viegas afirmou que a Defesa seria o teto da casa integrativa e, portanto, só tardiamente seria objeto de preocupação. Já criticamos esse pensamento de Viegas - o qual ele talvez já não defenda - por considerar que os fundamentos mais sólidos para qualquer construção integrativa são os políticos e, entre estes, os mais consistentes são os compromissos na área da Defesa. Por isso as aproximaçôes nessa área são parcimoniosas, pois uma vez avançado nela é difícil retroceder.
} 
Comissão Econômica para a América Latina e o Caribe (CEPAL); e c) analisamos as medidas de confiança do CDS-UNASUL entre os anos 2009 a 2012. Como fontes, utilizamos documentos e relatórios disponibilizados por entidades oficiais, entrevistas realizadas com atores e acadêmicos, bem como pareceres de especialistas sul-americanos e artigos e livros publicados sobre o tema.

\section{América do Sul no caminho multilateral da cooperação em Defesa}

Nas últimas duas décadas das relações interamericanas, proliferaram acordos nos âmbitos da Segurança e da Defesa, muitos deles para fomentar as "medidas de confiança" entre os Estados. Por "medidas de confiança em defesa" entendemos os processos políticos e/ou militares que objetivam mitigar e prevenir os efeitos negativos ou percepções erradas decorrentes dos "dilemas de segurança" nas relações internacionais. Exemplos desses efeitos negativos são, entre outros, as corridas armamentistas, a militarização de regiōes de fronteira, as incursões armadas e as violaçôes de soberania territorial dos Estados por parte das Forças Armadas (FA) estrangeiras.

No contexto interamericano do pós-Guerra Fria, houve duas modalidades principais de acordos sobre medidas de confiança: a multilateral e a bilateral. As CMDAs exemplificam a modalidade multilateral. Como caso bilateral e no ambiente sul-americano, destacamos os acordos entre Chile e Argentina que se constituíram no marco daquele momento: iniciados ainda na década de 1980, a partir da metade final dos anos 1990 eles transcenderam a bilateralidade (Caro 1994) ao envolver o CEPAL na construção de uma metodologia conjunta de aferição de gastos em defesa a ser aplicada a ambos e, quiçá, a outros Estados americanos. A importância e sucesso das medidas entre Argentina e Chile teve sua culminação, em agosto de 2005, com a criação da Brigada Cruz del Sur, uma Força de Paz Conjunta e Combinada, com sede em Santiago do Chile, para atuar bilateralmente em missões de paz da ONU.

Durante os anos 2000 ocorreram crises de segurança que evidenciaram a fragilidade dos processos hemisféricos vigentes de cooperação em defesa. Essas situações permitiram aos governos constatar uma preocupante morosidade dos foros e instrumentos de segurança interamericana para lidar com situações de crise. A percepção dessa fragilidade talvez explique a busca de uma nova via de cooperação multilateral e um foro regional de antecipação, prevenção e resolução de conflitos e crises na América do Sul.

Um evento relevante para a segurança regional foi o ataque das FA colombianas sobre um acampamento guerrilheiro no território equatoriano da Angostura, em março de 2008, que resultou no assassinato de Raul Reyes, uma liderança das Forças Armadas Revolucionárias da Colômbia (FARC) àquela época. Para a maioria dos governos sul-americanos, as tentativas de condenar a Colômbia pelo ataque foram emperradas pela posição discordante do governo Bush dos Estados Unidos, visto como a principal causa da morosidade da Organização 
dos Estados Americanos (OEA) para resolver a crise e cobrar do governo Uribe garantias de que não voltaria a violar a soberania territorial de seus vizinhos. Em contrapartida à morosidade, o governo de Luiz Inácio Lula da Silva, por intermédio de seu então ministro da Defesa, Nelson Jobim, articulou a proposta de criação de um Conselho Sul-americano de Defesa (CSD) no âmbito da UNASUL. Este funcionaria como um foro de alto nível regional que permitiria aos governantes sul-americanos resolver suas situaçóes de crises de segurança de maneira autônoma e sem intervençôes extrarregionais, assim como avançar nos seus processos de medidas de confiança como condição de possibilidade para uma futura comunidade de segurança regional.

Outra crise de segurança regional, quase um ano após o bombardeio em Angostura, foi a declaração dos presidentes Uribe, da Colômbia, e Bush, dos Estados Unidos, de que celebrariam amplos acordos que incluíam o uso de bases militares colombianas por militares norte-americanos. Essa possibilidade tornava-se estratégica para a projeção militar norte-americana na América do Sul ante a iminência da sua retirada do complexo militar de Manta, Equador. Alarmados com a possibilidade do aumento da presença militar extrarregional na Colômbia e sua potencial projeção sul-americana, os chefes de Estado da UNASUL convocaram uma Cúpula Extraordinária em Bariloche, Argentina, para solicitar maior transparência dos governos da Colômbia e dos EUA nos objetivos e parâmetros desse acordo. Ainda que não tenha sido assinado nenhum documento final, o resultado político dessa Cúpula foi claramente significativo: pela primeira vez conseguiu-se reunir com sucesso todos os Chefes de Estado da região (inclusive o presidente Uribe, nesse momento demandado) para debater questôes de defesa regional, sem a participação de potências extrarregionais e com transmissão televisionada ao vivo. Mais uma vez, não obstante a ausência de resolução, o ambiente diplomático-estratégico compeliu a Colômbia e os EUA a agirem de maneira mais cautelosa e a divulgarem aos demais governos o teor de seus acordos militares; conforme avaliou um ano depois em seu relatório a então ministra da Defesa da Argentina, Nilda Garré (Garré 2010).

Assim, a tendência principal que esses eventos ${ }^{2}$ inauguraram dentro da UNASUL foi traduzido na elaboração e adoção de novas medidas multilaterais de confiança, como a prática do CDS, que buscava aprimorar as experiências bilaterais e multilaterais dos governos, sobretudo aquelas concernentes aos gastos em defesa. O principal motivo alegado pelas autoridades políticas da UNASUL, ao apontarem a metodologia de aferição de gastos como elemento primordial das medidas de confiança, foi melhorar a transparência e a responsabilidade fiscal, não apenas entre os Estados e Governos da região, mas também entre estes e suas sociedades. Somado a isso, as informaçóes que as sociedades conseguem de seus próprios governos também acabam interligadas, em crescente efeito transnacional,

2 Outro evento não menos importante ocorreu na Medialuna de Pando, na Bolívia, como consta no site do MRE, disponível em <http://www.itamaraty.gov.br/temas/america-do-sul-e-integracao-regional/unasul>, acesso em 6 de junho de 2013. 
pelo uso dos novos meios de comunicação em redes sociais e de informação e da melhora da mobilidade das pessoas dentro e entre os Estados sul-americanos, gerando maior transparência, aguçando as percepções de segurança e defesa e mitigando os efeitos dos dilemas de segurança.

\section{Panorama dos processos interamericanos de medidas de confiança nas CMDA}

Com a dissolução do conflito bipolar da Guerra Fria, a potência momentaneamente solitária na sua hegemonia alterou a retórica da estratégica internacional em função das "emergências das novas ameaças". Com relação ao seu hemisfério, a hiperpotência procurou reestabelecer o controle ajustando o cabresto estratégico sobre a correlação de forças regionais. Com esse objetivo, impulsionaram a iniciativa para constituir um foro que permitisse definir conceitos, discutir procedimentos e propor políticas acordadas de Defesa com alcance hemisférico. O primeiro foro interamericano específico da Defesa, criado com esse objetivo, foram as Conferências de Ministros de Defesa das Américas (CMDA). Essas Conferências surgiram para promover as medidas de confiança na era do "pósGuerra Fria", quase ao mesmo tempo que outras propostas multilaterais, das quais uma é a própria criação da Área de Livre Comércio das Américas (ALCA) - que já era defendida pelo governo republicano de George Bush. Os objetivos políticos centrais das primeiras CMDAs foram a tentativa norte-americana de impor uma agenda de defesa comum para todo o continente fundamentada nas ameaças "compartilhadas"; ${ }^{3}$ reforçar o compromisso democrático (introduzido pela OEA em 1985); demonstrar a fundamental importância das FA e das forças de segurança para a defesa dos interesses dos Estados democráticos; propiciar maior transparência nos assuntos de defesa, como fortalecimento da segurança coletiva; chamar a atenção para o fato de que o "narco-terrorismo" era naquele momento a principal ameaça à segurança hemisférica (Mathias 2003).

As medidas de confiança em defesa, em especial a publicação dos gastos como instrumento de transparência, tiveram destaque especial a partir da V CMDA, realizada em 2002 no Chile. Nesta CMDA os governos assumiram a metodologia da CEPAL de cálculo de gastos militares, empregada com êxito entre Argentina e Chile, para ser ampliada aos demais Estados do hemisfério. Para mapear os temas tratados nas diferentes CMDA, desde 1995 até 2010, e que incidem diretamente sobre nosso objeto de análise, depuramos o quadro geral elaborado por Torres (2011), no qual priorizamos os temas de medidas de confiança, mediçóes em gastos de defesa (tema recorrente desde a III CMDA), e o da multidimensionalidade e novas ameaças (Tabela 1).

3 Criticamos esta concepção no capítulo intitulado "Reconceitualizando as Novas Ameaças: da subjetividade da percepção à segurança cooperativa” no livro compilado por Samuel Alvares Soares; Suzeley Kalil Mathias: Novas Ameaças: Dimensões e Perspectivas. Desafios para a cooperação em defesa entre Brasil e Argentina. São Paulo: Sicureza, 2003. 


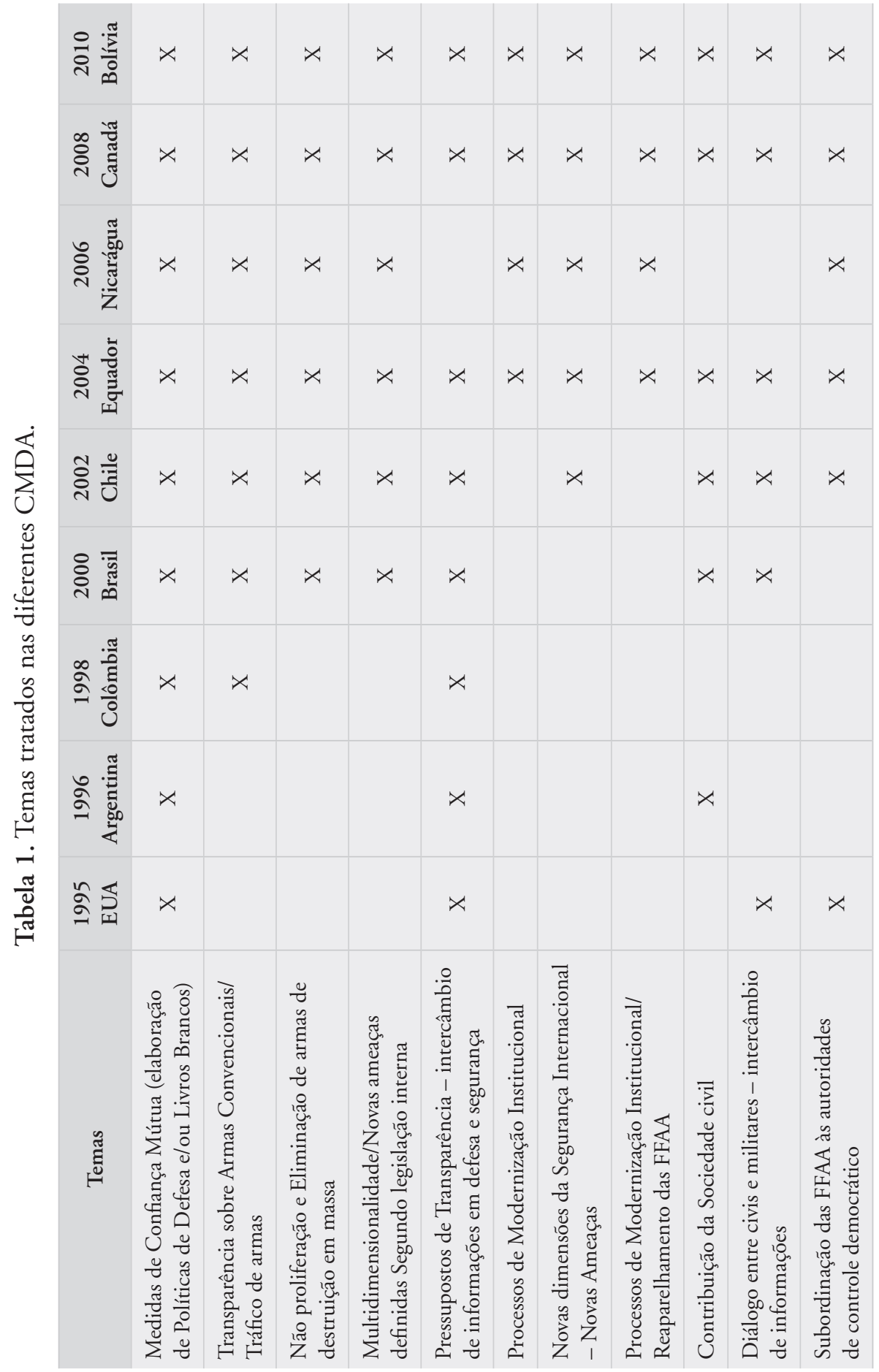




\section{A metodologia CEPAL de gastos em defesa Argentina-Chile}

Os antecedentes diretos que possibilitaram a criação da metodologia da CEPAL para gastos em defesa entre o Chile e a Argentina foram os processos de elaboração de seus Livros Brancos da Defesa (LBD) nos anos de 1997 e 1999, respectivamente. Os LBDs são documentos oficiais elaborados e publicados pelos governos que trazem diversas informações sobre suas particulares percepções de ameaças, suas capacidades e vulnerabilidades, sua projeção estratégica nacional e a sua defesa. Alguns deles fazem referência direta aos orçamentos nacionais destinados ao setor de Defesa. Porém, ainda que sejam importantes instrumentos de transparência, os LBDs encerram algumas dificuldades para comparar gastos entre os Estados, ainda que não seja esse o seu objetivo primordial. Entre outros aspectos, as principais dificuldades do uso dos LBDs para efeitos de comparação orçamentária são: a) os anos fiscais nem sempre são compatíveis entre os Estados; b) os gastos são cotados em moeda local ou em câmbios locais em relação ao dólar; c) as fontes de orçamento nem sempre são compatíveis; d) as atribuições diferentes das funções das FA e dos corpos policiais que podem depender dos Ministérios da Defesa ou de Segurança Interior; e e) por vezes há fontes específicas de orçamento, como as reservas que provinham da "Lei do Cobre" no Chile (Scheetz 2004).

Por essas dificuldades e tentando desenvolver uma metodologia conjunta para facilitar análises comparadas, realizou-se a Quinta Reunião da Comissão Permanente de Segurança Argentino-chilena (COMPERSEG), realizada em Buenos Aires em 16 e 17 de julho de 1998. Nessa reunião, a Comissão decidiu solicitar o auxilio da CEPAL para elaborar uma metodologia comum de cálculo de gastos. A proposta foi formalizada na petição do grupo " $2+2$ ", composto pelos ministros de Relações Exteriores e de Defesa de ambos os países, para a SecretariaExecutiva da CEPAL. Em 16 de fevereiro de 1999, na declaração conjunta dos presidentes do Chile, Eduardo Frei Ruiz-Tagle, e da Argentina, Carlos Saúl Menem, em Ushuaia, os mandatários reafirmaram seu compromisso com a construção de medidas de confiança em defesa e seu apoio aos trabalhos que a CEPAL iniciaria, até mesmo financiando os gastos da pesquisa a ser realizada (Gazzotti 2005). Como consequência, as partes e a CEPAL criaram um Grupo Assessor ad hoc, responsável pelas pesquisas preliminares, que teve destacado papel no acesso a importantes informações, pois contou com a colaboração e a vontade política das partes. O resultado desse trabalho foi um documento conhecido nos relatórios da CEPAL com a alcunha de "Non-Paper", revisado pelas partes e aceito como base dos estudos pelas delegações da Argentina, do Chile e da CEPAL para, finalmente, divulgar a versão final em novembro de 2001.

Quanto à metodologia da CEPAL, seu desafio inicial foi basicamente conceitual, ocupando-se em definir o escopo do que as partes entendiam como questôes relativas à defesa. Nesse caso, diferente daquilo que propuseram os EUA nas CDMA que tornava difuso, ou mesmo nulo, o limite entre os conceitos de 
"segurança" e de "defesa", às vezes solapado com neologismos como o da "segurança multidimensional" ", os integrantes do Grupo ad hoc optaram por limitar o escopo da defesa à manutenção da "segurança externa" do Estado entendida como:

O conjunto de atividades cujo efeito é salvaguardar a soberania nacional. Seu objetivo é alcançar uma condição de segurança externa de modo que o país possa realizar seus Objetivos Nacionais... Concordante com o anterior, gasto em defesa é aquele em que incorre o país para materializar o objetivo proposto no parágrafo anterior. (relatório CEPAL de gastos em Defesa)

Baseados nessa definição, consideraram a aferição dos gastos em termos de fluxos monetários e não de ativos físicos e financeiros acumulados em períodos mais longos, tal como alguns Estados já fazem em processos de transparência de gastos de governos que são enviados às instituições internacionais como a Organização das Nações Unidas (ONU) ou o Fundo Monetário Internacional (FMI). A segunda medida foi a de quantificar e compatibilizar os gastos, considerando que os processos internos são distintos e que o projeto CEPAL não ambicionava alterá-los. Quanto ao método de aferição, o Grupo optou por dividir os gastos em três esferas que se somam e complementam progressivamente (relatório CEPAL):

- G1 - Básico. Gastos governamentais em toda a Administração e gestão da defesa militar, especialmente a administração, supervisão e gestão dos assuntos das forças: terra, mar, ar e espaço; engenharia de transportes, comunicações, informações, materiais, pessoal e outras forças e comandos não combatentes; forças de reservas e auxiliares vinculadas ao sistema de defesa, e abastecimento de equipamento e estruturas militares.

- G2 - Ampliado. Como na Argentina e no Chile, os gastos em G1 não incluem os gastos previsionales de las Fuerzas Armadas são incorporados neste nível G2 Ampliado. Assim, este resulta diretamente do nível G1 Básico somado aos gastos previsionales que são os gastos de pessoal, aposentadorias ou previdência social. A partir desse momento são incluídos os gastos previdenciários líquidos das FA, que fazem parte do conjunto dos gastos previdenciários totais dos governos.

- G3-Total. Neste nível é somado ao G1 e G2 aquilo que os governos definiram como gastos em "Indústria de Defesa e Pesquisa e Desenvolvimento"; outras atividades produtivas, atividades de defesa e ajuda militar. No relatório final, a Secretaria da CEPAL admitiu não haver conseguido compilar dados de um período maior de tempo para padronizar as variações nestes gastos.

4 Analisamos criticamente este conceito em SAINT-PIERRE, Héctor L. "'Defesa' ou 'Segurança'? Reflexōes em torno de Conceitos e Ideologias" in Contexto internacional, ISSN 0102.8529, PUC-Rio, junho/dezembro 2011 - Vol 33, pp. 407-435. 
Destes três níveis de gastos pesquisados, o G3 foi o que encerrou maiores dificuldades de quantificação. Ponto de destaque foi o caso singular do Chile, que durante a construção da metodologia contava com uma Indústria de Defesa baseada em fontes quase autônomas, mas que, ainda assim, dependiam do Ministério da Defesa, razão pela qual foram desconsideradas. ${ }^{5}$

Quanto à distribuição dos gastos, o relatório diagnosticou que não havia clima armamentista ou de militarização entre Argentina e Chile. Isto porque identificaram, comparativamente, que a maior parte dos gastos dos ministérios da Defesa estava concentrada no nível G2, referente às questôes previdenciárias. A recomendação do Grupo foi que os Ministérios da Defesa adotassem medidas progressivas de modernização de suas estruturas e processos. Em linhas gerais, a metodologia CEPAL para aferição dos gastos em defesa entre Argentina e Chile serviria de base para o modelo a ser adotado uma década depois pelas CMDA e pelo CDS.

\section{As medidas de confiança adotadas pelo CDS-UNASUL entre os anos 2009 a 2012}

Dois acontecimentos regionais incidiram fortemente na criação e consolidação do CDS: o bombardeio colombiano em Angostura, Equador, em 2008 e os acordos sobre as bases militares Colômbia-EUA (Palacios 2011a, 2011b). Esses eventos permitem vislumbrar a própria gênese do CDS como a institucionalização da expressão política de uma vontade regional que se propõe a resolver os conflitos sul-americanos autonomamente, sem ingerência de atores extrarregionais e que, uma vez criado, poderia desenvolver e aprimorar instrumentos e métodos específicos de confiança para os âmbitos estratégico e tático (Donadio 2010).

De uma perspectiva mais ampla, o processo de construção e consolidação das medidas de confiança da UNASUL pode ser dividido cronologicamente em duas etapas: a) desde a criação do CDS em 2008 até a inauguração do Centro de Estudos Estratégicos da Defesa (CEED) em 2009; e b) a partir de 2009, com a promoção da série de Seminários sobre "modernização dos ministérios de defesa", até 2012, com as tentativas do CEED para criar uma metodologia comum para aferição dos gastos em defesa na região (Ríal 2010). Da primeira etapa, destacamos alguns pontos formais sobre o CEED, uma vez que foi o órgão multilateral incumbido de elaborar as "medidas de confiança" e o desenvolvimento da metodologia para gastos em defesa da UNASUL.

Em janeiro de 2009, a delegação argentina na UNASUL elaborou uma proposta de criação de um Centro Sul-americano de Estudos Estratégicos para a Defesa (CEED) sob a órbita do CDS. Esse Centro serviria como instância de

5 Foi o caso das Fábricas y Maestranzas del Ejército (FAMAE), vinculadas à Subsecretaría de Guerra; Astilleros y Maestranzas de la Armada (ASMAR), relacionada com a Subsecretaría de Marina; e a Empresa Nacional de Aeronáutica (ENAER), dentro da Subsecretaría de Aviación. 
assessoramento e consulta em matéria de defesa para o Conselho. A proposta argentina esclarecia que o CEED não teria o objetivo de substituir os Centros de Estudos Estratégicos Nacionais, mas sim de trabalhar em conjunto com eles. Para a conformação do pessoal, foi proposto que sejam militares e civis envolvidos com pesquisas e atuação profissional no âmbito da defesa, sendo designados pelos Ministros da Defesa. Sua estrutura estaria constituída por uma Junta Diretiva, formada pelos membros da instância executiva do CDS, e uma Junta Executiva, formada por um Diretor ${ }^{6}$ e um Subdiretor de nacionalidades diferentes e eleitos pela Junta Diretiva. Também foi proposto que a sede permanente e física do Centro seja em Buenos Aires, Argentina; o orçamento do Órgão é votado pelas contribuições dos Ministérios da Defesa participantes do CDS, por intermédio da Secretaria-Geral da UNASUL, comprometendo-se a República Argentina a financiar a estrutura básica de funcionamento do Órgão.

A formalização da proposta do CEED foi feita na primeira Reunião de Ministros e Ministras da Defesa do CDS em Santiago do Chile, nos dias 9 e 10 de março de 2009. Nessa reunião foi declarado, sob o tema de Formação e Capacitação, o apoio dos Estados-membros para a criação do CEED. A partir desse momento, estabeleceram um plano de ações prévias à criação do Centro: a) elaborar um registro das academias e centros de estudos de defesa e de seus programas, ou seja, criar uma rede sul-americana interligando os centros de capacitação e formação em defesa; b) constituir o CEED e encarregar a um grupo de trabalho, em um prazo de 60 dias, a elaboração do estatuto do Centro; c) realizar durante novembro de 2009, no Rio de Janeiro, o Primeiro Encontro Sul-americano de Estudos Estratégicos. O tópico a) ficou a cargo do governo da Venezuela; o b) foi realizado na Argentina com um grupo de trabalho multidisciplinar composto por militares, acadêmicos e também por funcionários do Ministério da Defesa; por fim, o tópico c) ficou a cargo da Argentina, do Brasil e do Chile sob a responsabilidade do Brasil, que encarregou a coordenação do encontro à Escola Superior de Guerra (ESG) com mínima participação dos representantes sul-americanos na organização do evento (Palacios 2011b).

Ao mesmo tempo em que a proposta do CEED era formalizada e sua criação autorizada, o CDS promoveu uma série de Seminários em Defesa com funcionários de governo, de Estado e acadêmicos para debater a modernização dos ministérios da Defesa e avançar nas medidas de confiança. Esses objetivos foram incorporados ao Plano de Ação de 2009-2010, criando também diferentes Grupos de Trabalho encarregados de realizar aqueles objetivos, por exemplo, Chile-Peru ${ }^{7}$ no tema de gastos em Defesa (Saint-Pierre 2009a). Dos relatórios produzidos nos Seminários,

6 Elegeram como Diretor o Secretário de Assuntos Internacionais (nível de vice-ministro) do Ministério da Defesa da Argentina, Alfredo Forti, que teve seu mandato renovado até 2015 e, como Subdiretor, o equatoriano Dr. Pablo Celli de la Torre.

7 A comissão para esse tema foi composta justamente por estes dois Estados, cujas tensões militares por limites territoriais são históricas, fomentando efeitos políticos benéficos para a transparência entre as partes. 
o segundo é o que mais nos interessa, pois dele emergem as duas características principais das medidas de confiança adotadas na UNASUL: a) a promoção dos LBD dos Estados-membros, e b) a escolha do sistema de divulgação em "gastos de defesa” como ferramenta principal de transparência (Saint-Pierre 2009b).

No tocante à primeira característica, a morosidade do Brasil em lançar o seu LBD foi percebida com desconfiança por seus vizinhos e afetou negativamente a consolidação da confiança regional. As causas apontadas para explicar a morosidade brasileira são: o desinteresse e/ou arrogância do Brasil em esclarecer aos seus vizinhos suas intençôes e a sua capacidade militar; os sentimentos de autonomia e disputa entre as três armas brasileiras que emperravam uma visão estratégica geral, como as resistências para a criação de um Estado-Maior Conjunto das FA; ${ }^{8}$ baixa prioridade outorgada nas questôes da Defesa pela classe política brasileira; e um insatisfatório índice de controle e participação civil na condução da Política de Defesa e mesmo entre os quadros funcionais do Ministério da Defesa. Não obstante as duas Políticas Nacionais de Defesa (PNDs) (Miyamoto 2004; Rizzo 2004) e a Estratégia Nacional de Defesa (END) (Rizzo 2009; Saint-Pierre 2009c) tenham esclarecido diversos pontos sobre a Defesa brasileira, esses documentos não possuem a clareza e o rigor metodológico para sistematizar as atividades de defesa e permitir o acompanhamento orçamentário. ${ }^{9}$

Quanto à divulgação multilateral dos gastos, as dificuldades para sua realização advêm em parte da difundida "cultura do segredo" envolvendo os "interesses nacionais", depois, na própria elaboração de uma metodologia comum, conforme comentado antes no caso da CEPAL. Porém, ainda que esta última dificuldade pareça ser de natureza apenas técnico-administrativa - a exemplo das decisões sobre os ajustes nos gastos em defesa a serem alocados nas esferas em G1, G2 e G3 -, houve uma inequívoca vontade política dos governantes sul-americanos para superar as dificuldades técnicas e iniciar a divulgação dessas informaçôes, não apenas entre os governos, mas também para a sociedade civil, conforme Celi (2010). Nesse aspecto, entretanto, são recorrentes e graves os problemas de comunicação do $\mathrm{CDS}^{10}$ que dificultam até mesmo a realização de pesquisa acadêmica sobre o tema: por exemplo, em 30 de maio de 2012, o CEED promoveu um seminário em Quito para apresentar os relatórios parciais dos gastos em Defesa dos

8 O Estado-Maior Conjunto das Forças Armadas (EMCFA), criado pela Lei Complementar no 136, de 25 de agosto de 2010, absorve todas as referências legais e atribuiçôes impostas ao extinto Estado-Maior de Defesa.

9 De acordo com os $\$ \$ 1^{\circ}, 2^{\circ}$ e $3^{\circ}$ do art. $9^{\circ}$ da Lei Complementar no 97 , de 9 de junho de 1999 , " $\$ 1^{\circ}$ Ao Ministro de Estado da Defesa compete a implantação do Livro Branco de Defesa Nacional, documento de caráter público, por meio do qual se permitirá o acesso ao amplo contexto da Estratégia de Defesa Nacional, em perspectiva de médio e longo prazos, que viabilize o acompanhamento do orçamento e do planejamento plurianual relativos ao setor." Disponível em: <http://www.defesa.gov.br/projetosweb/livrobranco/oquee_livrobranco.php>.

10 Com a exceção da presidência pro tempore de Equador, cujo ministro Javier Ponce dedicou-se às tarefas de consolidação do CDS, a divulgação do CDS caracteriza-se pelo descaso. Talvez o ponto culminante dessa situação foi haverem deixado de pagar o site do CDS e perdido o endereço de domínio. Resultado do fato de que o CDS não é tema prioritário para todos os Ministérios de Defesa da região. 
Estados-membros; ${ }^{11}$ porém, o website do CDS - que nem sempre está disponível apresenta apenas um relatório geral e preliminar dos gastos, enquanto os relatórios por Estado se encontravam em sistema de divulgação precária ou sob o título evasivo de "pendente de autorização" para consulta. Apesar dessas limitações, apuramos que a sua metodologia, compartilhada pelos 12 Estados-membro da Organização, é estruturada por três variáveis principais, conforme consta na Tabela 2:

\section{Tabela 2. Estrutura comum de gastos em Defesa.}

\begin{tabular}{|c|c|c|}
\hline $\begin{array}{c}\text { Definição comum } \\
\text { dos gastos em Defesa }\end{array}$ & $\begin{array}{l}\text { Metodologia padronizada } \\
\text { de apresentação }\end{array}$ & $\begin{array}{c}\text { Mecanismo anual } \\
\text { de remissão }\end{array}$ \\
\hline $\begin{array}{l}\text { Entendido como } \\
\text { todos os recursos } \\
\text { designados pelos } \\
\text { Estados, bem como } \\
\text { qualquer ajuda } \\
\text { externa (monetária } \\
\text { ou não) }\end{array}$ & $\begin{array}{l}\text { Classificação por objeto de gasto e instituição } \\
\text { executora. } \\
\text { Periodicidade anual seguindo o ano fiscal. } \\
\text { Fontes de financiamento orçamentárias e } \\
\text { extraorçamentárias. } \\
\text { Valores em moeda local e cotações em dólares. } \\
\text { Indicadores de referência como gastos de } \\
\text { defesa em relação ao PIB e ao Gasto Fiscal. }\end{array}$ & $\begin{array}{l}\text { Estabelece que os } \\
\text { Estados devem } \\
\text { remeter seus } \\
\text { relatórios anuais - } \\
\text { referentes ao ano } \\
\text { imediatamente } \\
\text { anterior - até o } \\
\text { dia } 31 \text { de julho de } \\
\text { cada ano }\end{array}$ \\
\hline
\end{tabular}

Fonte: <http://www.gedes.org.br/downloads/520ea114a42dd196326e02c61e275c1f.PDF>.

A partir dessas três variáveis são analisados os dados referentes ao período de 2006 a 2010. Nessa primeira etapa, os dados mostram o gasto total em defesa na América do Sul que, nestes cinco anos, foram de US\$ 126 bilhões. Desse total, $44 \%$ correspondem aos gastos do Brasil, $17 \%$ da Colômbia, 10,7\% da Venezuela, 9\% do Chile, 8,3\% da Argentina, 4,5\% do Equador e 4\% do Peru. Os demais Estados possuem gastos equivalentes a $1 \%$ ou menos do total regional.

Outro importante aspecto que pode ser notado nesse relatório foi a inserção oficial do chamado "objeto de gasto", ou tipo de atividade na qual foram realizados os gastos. No período analisado apuraram que 59\% dos gastos são referentes a pagamento de pessoal, $23,5 \%$ são de operações militares, $17,3 \%$ de investimentos e outros $0,5 \%$ são de pesquisas na área de defesa. Do item Investimentos, com $17,3 \%$ do montante, destacam-se três categorias: $45,2 \%$ são destinados ao Sistema de Armas, 12,3\% a Infraestrutura e outros $42,5 \%$ para Aquisiçôes de outros Equipamentos.

Conforme o parecer de José Goñi, ex-ministro da Defesa do Chile entre 2007 e 2009 (Goñi 2012), esses dados revelaram, por um lado, que há uma

11 Obtivemos esses dados em primeira mão por estarmos presentes nessa reunião, convidados para proferir uma conferência, e contar com a simpatia do secretariado que nos facilitou uma cópia. Como em quase todos os casos nesta área, o acessos aos dados é resultado de uma luta corpo a corpo pela informação. Acreditamos que por vezes é menos pela mística "cultura do segredo" e mais por disfunção comunicacional. 
desproporção significativa em investimentos de pessoal, responsável por quase metade dos gastos regionais e, por outro, a irrisória quantia destinada às pesquisas em Ciência e Tecnologia (C\&T) e Pesquisa e Desenvolvimento (P\&D) da área. Segundo ele, esse quadro precisa mudar e a região deve investir mais em pesquisas para aprimorar as capacidades em defesa e, desse modo, diminuir sua dependência estratégica de fornecedores externos de tecnologia. Nesse ponto, ressaltamos o perfil dos investimentos feitos com o orçamento em Defesa do Brasil, que perfaz $44 \%$ do volume total sul-americano para o setor. De acordo com as estimativas divulgadas no LBD do Brasil (LBDN 2012), com a metodologia empregada pelo Sistema Integrado de Administração Financeira do Governo Federal (SIAFI), no ano de 2011 , em média $75,3 \%$ do orçamento brasileiro de defesa foi destinado para o pagamento de pessoal e outros encargos sociais, perfazendo a maior fatia do orçamento da área. O restante fica dividido em 10,6\% para Investimentos, 13,2\% para Custeio e 1,0\% de Dívidas.

Segundo esse diagnóstico, alarma a desproporção da alocação orçamentária do Brasil, que podemos considerar a partir de dois pontos de vista em relação à mesma tendência constatada em toda a América do Sul: por um lado, o Brasil segue a tendência sul-americana de alocar a maior parte dos seus recursos da Defesa para pagamento de pessoal e seus encargos sociais, o que não representaria uma "exceção à regra regional". Por outro lado, sendo o Brasil responsável por 44\% do orçamento em defesa regional, nos indagamos se, antes de seguir a tendência dos seus vizinhos, não será ele próprio quem imprime essa tendência à região, visto que seus gastos com pessoal constituem $75,3 \%$ dos $44 \%$ do gasto total regional.

$\mathrm{O}$ caso brasileiro do orçamento de Defesa aparece distorcido não apenas pelo pagamento de salários, mas sobretudo pelos encargos previdenciários. Não obstante a gritante distorção, está se formando um "consenso" sobre a necessidade política de aumentar o percentual destinado ao orçamento da Defesa brasileira. Todavia, sobre essa pretensão, Almeida (2005), do Tribunal de Contas da União (TCU), alerta para que antes de o governo brasileiro destinar mais recursos para a Defesa, é necessário modernizar o seu Ministério e suas Forças Armadas, exigindo melhor uso dos recursos públicos já alocados, como condição indispensável para o aumento e repasse de novos recursos. ${ }^{12}$

12 A desproporção de gastos o para pagamento de pessoal e seus encargos sociais não é exclusivo do Brasil ou mesmo da América Latina. O caso dos EUA é emblemático: apesar de ser o Estado que mais investe em Defesa, a maior parte do seu orçamento em Defesa é destinado ao pagamento de pessoal e encargos sociais. Porém, desde 2003 os EUA enviaram regimentos expedicionários para ao menos duas guerras, a do Afeganistão e a do Iraque. Mesmo assim, a desproporção norte-americana em relação aos objetos de gasto em Defesa não é tão discrepante como na América do Sul. Para uma visão abrangente e didática do orçamento e gastos em defesa dos EUA recomendamos a reportagem especial produzida pelo Washington Post, disponível em <http://www. washingtonpost.com/blogs/wonkblog/wp/2013/01/07/everything-chuck-hagel-needs-to-know-about-thedefense-budget-in-charts/>, acesso em 1 de agosto de 2013. 


\section{Considerações finais}

Ao analisarmos as principais ações e resultados das medidas de confiança adotadas pelo CDS entre os anos de 2009 a 2012, conforme os Planos de Ação acordados entre as partes, percebe-se que os processos de medidas de confiança em defesa da UNASUL não apresentam grandes inovações metodológicas e ainda seguem os delineamentos da ONU, OEA e CEPAL. Os principais elementos que apontam a continuidade quanto ao conteúdo são o foco na elaboração dos chamados Livros Brancos da Defesa e a importância concedida à transparência dos gastos em defesa. Quanto à forma do processo, a continuidade está na participação ainda embrionária ou nula das sociedades civis sul-americanas nos debates, caracterizando um processo vertical que reflete, em alguns casos, a persistência de ilhas de autonomia militar nos temas de Defesa e a ausência de acadêmicos do tema.

Os relatórios preliminares de gastos em defesa permitem uma percepção em parte alentadora: apesar de os gastos em defesa da América do Sul aumentarem comparativamente à média mundial no período analisado, quando esse fenômeno é contextualizado, percebe-se que esse período foi influenciado pela crise financeira de 2008. Essa crise resultou numa significativa retração dos gastos em Defesa, tanto nos EUA quanto na Uniāo Europeia (UE), decorrente das chamadas "medidas de austeridade fiscal", o que evidenciou os gastos da América do Sul. De outra parte, o significado estratégico do aumento de gastos em defesa em América do Sul não satisfaz aos critérios (Buzan 1987) que caracterizariam uma "corrida armamentista" na região, nem representa níveis preocupantes de militarização entre os Estados.

Da análise dos relatórios e documentos ficamos com a impressão de que as FA sul-americanas estão de fato "inchadas" com o gasto de pessoal que consome a maior parte do orçamento, ao passo que sua capacidade em termos de pesquisa e tecnologia e de equipamentos militares e até sua capacidade de defesa são deficitárias. Não raro, as folhas de pagamento com pessoal, que consomem o orçamento, prejudicam a modernização e profissionalização dos recursos humanos, o desenvolvimento de novos produtos de Defesa e a harmonização de um dispositivo de forças armadas sul-americanas operacional e funcional à Defesa da região. Acreditamos que essa situação poderia ser atenuada com maior envolvimento das Universidades e da sociedade civil nas questôes da Defesa, especialmente no campo da elaboração das Políticas de Defesa e na promoção de Pesquisa e Desenvolvimento (P\&D) dos produtos de Defesa. Por esse caminho, diminuiria a dependência da América do Sul das potencias extrarregionais em prover produtos e tecnologia em Defesa.

Considerando a desproporção nos objetos de gastos em defesa, pode-se concluir que, independentemente da quantidade, os governos gastam mal. No campo das aquisições de equipamentos bélicos, as compras parecem obedecer mais ao "mercado de oportunidades" circunstancial, à recuperação de material obsoleto, 
às inércias das demandas burocráticas, ou ainda como uma maneira de acalmar a tropa com novos "brinquedos", como dizia Huntington (1964), do que a uma tendência de visão propositiva, cuja reflexão estratégica leve em conta a vontade política manifestada pelos mandatários pela cooperação regional.

O hiato entre as declarações políticas e as ações de cooperação em Defesa é agravado pelo fato de que não foram elaboradas e assimiladas novas doutrinas para a cooperação sul-americana. Em linhas gerais, os desenhos estratégicos ainda refletem anacronicamente as expectativas anteriores ao fim da Guerra Fria. $\mathrm{Na}$ verdade, esse fato, embora denuncie um paradoxo, não deve surpreender. Como dissemos noutro lado (Saint-Pierre 2007), os diferentes estágios no empoderamento da condução política da Defesa, que pode ser visto como um fenômeno de relações civis-militares e também como um problema de governabilidade, mostra-nos poucos casos sul-americanos nos quais amadureceu o controle civil sobre os militares e se consolidou a formulação e condução política da defesa. Por isso, as atitudes que apontam para a cooperação regional na área da Defesa limitam-se a gestos de construção da confiança, ainda muito distantes de obedecerem a um desenho coerente com um processo cooperativo. $\mathrm{Na}$ maior parte da região os militares ainda gozam de prerrogativas e/ou ambiguidades constitucionais que garantem sua autonomia decisória em relação ao Estado. Essa autonomia contribui para que prevaleçam os interesses corporativos das FA sobre o alinhamento estratégico da burocracia em relação aos fins definidos pela política. Cegos para uma visão cooperativa regional, atordoados pelas medidas de confiança assumidas pelos governos, os militares acabam por se aferrar às velhas fórmulas de projeção de poder e a anacrônicos esquemas dissuasórios.

Deixando de fora os preocupantes gastos com pessoal, os investimentos aplicados em manutenção, renovação e inovação do material militar sul-americano não são exagerados, nem sequer alarmantes em relação ao percentual mundial. Todavia, sem levar em conta a nova realidade política cooperativa da região, suas vulnerabilidades e potencialidades, sem desenhar regionalmente os cenários projetivos, sem refletir profundamente nos interesses nacionais e regionais, sem pensar seriamente nos meios e no preparo adequados para enfrentar a latência de velhas ameaças e a convergência das novas, esses gastos não são excessivos, são simplesmente um desperdício.

\section{Referências bibliográficas}

ALMEIDA, Carlos Wellington de (2005) "Transparência do orçamento de defesa: o caso brasileiro” Papeles de investigación RESDAL, agosto 2005. Disponível em: http://www.resdal. org/presupuestos/caso-brasil.pdf. Acesso realizado em 28/06/2012.

BUZAN, Barry (1987) An introduction to strategic studies: military technology and international relations. Ed. Macmillan - International Institute for Strategic Studies, 1987. 
CARO, Isaac (1994) “Medidas de Confianza Mutua en América del Sur" NUEVA SOCIEDAD NRO. 132 JULIO-AGOSTO 1994 , PP. 44-51.

CELI, Pablo (2010) "Medidas de confianza y prevención de conflictos en el actual contexto regional”. In CONFIANZA Y SEGURIDAD ENAMÉRICA DEL SUR. Publicación del Consejo de Defensa Suramericano, Quito outubro 2010. Disponível em: http:/www.unasurcds.org/ index.php?option=com_content $\&$ view=article $\&$ id $=85 \% 3$ Acuadernos-de-defensa-no-2-enamerica-confianza-y-seguridad-del-sur- $\&$ catid=48\%3Apublicaciones \&Itemid=225\&lang=pt. Acesso em 20/06/2012.

DONADIO, Marcela (2010) "El Consejo Sudamericano de Defensa y papel en el desarrollo de la confianza mútua”. In CONFIANZA Y SEGURIDAD EN AMÉRICA DEL SUR. Publicación del Consejo de Defensa Suramericano, Quito outubro 2010.Disponível em: http://www.unasurcds.org/index.php?option=com_content\&view=article\&id=85\%3Acuader nos-de-defensa-no-2-en-america-confianza-y-seguridad-del-sur- $\&$ catid=48\%3Apublicaciones \&Itemid=225\&lang=pt. Acesso 20/06/2012.

GARRÉ, Nilda (2010) "La Cumbre de Bariloche y su impacto en la consolidación de la paz y seguridad en Sudamérica”. In CONFIANZA Y SEGURIDAD EN AMÉRICA DEL SUR. Publicación del Consejo de Defensa Suramericano, Quito outubro 2010.Disponível em: http://www.unasurcds.org/index.php?option=com_content\&view=article\&id=85\%3Acuader nos-de-defensa-no-2-en-america-confianza-y-seguridad-del-sur- $\&$ catid=48\%3Apublicaciones \&Itemid=225\&lang=pt. Acesso realizado em 20/06/2012.

GAZZOTTI, Hebe (2005) "Medidas de fomento de confianza en defensa y seguridad: la experiencia del Cono Sur”. NDU Digital Library Archives, 2005. Disponível em: http://digitalndulibrary. ndu.edu/cdm4/document.php?CISOROOT=/chdspubs\&CISOPTR=3074\&REC $=1$. Acessado em 20/05/2012.

GOÑI, José (2012) “Gastos sudamericanos en defensa: hacia más integración”. Disponível em: http://www.elquintopoder.cl/politica/gasto-sudamericano-en-defensa-hacia-mas-integracion/. Acesso 18/06/2012.

HUNTINGTON, Samuel (1964) The Soldier And The State - The Theory and Politics of CivilMilitary Relations. Vintage Books, 1964.

MATHIAS, Suzeley Khalil (2003) "Defesa e segurança hemisférica: um tema controverso. Notas à declaração sobre segurança nas Américas”. Informes RESDAL, dezembro de 2003. Disponível em: http://www.resdal.org.ar/ultimos-documentos/art-news-kalil.html. Acessado em 15/03/2012.

MIYAMOTO, Shiguenoli (2004) "A Política Brasileira de Defesa e Segurança: algumas considerações”. In O Brasil no cenário internacional de defesa e segurança. organizadores: J.R. de Almeida Pinto, A.J. Ramalho da Rocha, R. Doring Pinho da Silva. - Brasília: Ministério da Defesa, Secretaria de Estudos e de Cooperação, 2004. Disponível em: http://www.defesa.gov. br/arquivos/colecao/brasil.pdf. Acesso realizado em 15/-06/2012.

PALACIOS Jr, Alberto Montoya Correa; GONZÁLEZ, Laura C. (2011a) "Estados falidos e áreas não governadas na América do Sul: caso da fronteira Colombia-Equador”. In MEDINA, Cremilda.(org) Fronteiras latino-americanas, Geopolítica do século XXI.”. São Paulo. Fundação Memorial América Latina/Cátedra UNESCO. 
. (2011b) “Os desafios da criação do Centro de Estudos Estratégicos da Defesa (CEED-UNASUR) e a integração de defesa na América do Sul” In: ALVES, Vágner Camilo; MOREIRA, William de Souza; NETO, Miguel Arias..(Org.) A defesa e a segurança na América do Sul: IV Encontro da ABED. Campinas: Mercado das Letras, p. 59-73.

RÍAL, Juan (2010) "Institucionalización de medidas de confianza mutua de comienzos de la segunda década del siglo XXI: una propuesta de Consejo de Defensa Suramericano". In CONFIANZA Y SEGURIDAD EN AMÉRICA DEL SUR. Publicación del Consejo de Defensa Suramericano, Quito outubro 2010.Disponívelem: http://www.unasurcds.org/index. php?option=com_content \&view=article $\&$ id $=85 \% 3$ Acuadernos-de-defensa-no-2-en-americaconfianza-y-seguridad-del-sur- $\&$ catid $=48 \% 3$ Apublicaciones $\&$ Itemid $=225 \&$ lang=pt. Acesso em 20/06/2012.

RIZZO, Eliézer (2009) "A Estratégia Nacional de Defesa e a reorganização e transformação das Forças Armadas" 2009. Disponível em: http://interessenacional.uol.com.br/2009/04/aestrategia-nacional-de-defesa-e-a-reorganizacao-e-transformacao-das-forcas-armadas/. Acessorealizadoem 18/06/2012.

(2004) O Brasil diante dos desafios internacionais de Segurança e Defesa: um enfoque hemisférico. In $O$ Brasil no cenário internacional de defesa e segurança. organizadores: J.R. de Almeida Pinto, A.J. Ramalho da Rocha, R. Doring Pinho da Silva. - Brasília :Ministério da Defesa, Secretaria de Estudos e de Cooperação, 2004.Disponívelem: http://www.defesa.gov. br/arquivos/colecao/brasil.pdf.Acessorealiazadoem 15/06/2012.

SAINT-PIERRE, Héctor. (2003) "Reconceitualizando as Novas Ameaças: da subjetividade da percepção à segurança cooperativa” in Soares, Samuel; Mathias, Suzeley (orgs.): Novas Ameaças: Dimensões e Perspectivas. Desafios para a cooperação em defesa entre Brasil e Argentina. São Paulo: Sicureza.

. (organizador) (2007) Controle civil sobre os militares e política de defesa na Argentina, no Brasil, no Chile e no Uruguai. São Paulo: UNESP.

. (2009a) “Consideraciones de la profesionalización del personal de la Defensa”. In Memórias del Seminário “Modernización de los Ministérios de Defensa”. Quito, 2009a. Disponível em: http://www.unasurcds.org/index.php?option=com_content\&view=art icle\&id $=212 \% 3$ Amemoriasmodernizacionministeriosdefensa\&catid=48\%3Apublicaciones $\& \mathrm{I}$ temid=225\&lang=pt. Acesso realizado em 16/06/2012.

.(2009b) "La naturaleza política de la Defensa”. In Memórias del Seminário

"Modernización de los Ministérios de Defensa”. Quito, 2009b. http://www.unasurcds.org/index. php?option=com_content $\&$ view=article $\&$ id $=212 \% 3$ Amemoriasmodernizacionministeriosdef ensa\&catid $=48 \% 3$ Apublicaciones $\&$ Itemid $=225 \&$ lang=pt.

(2009c) "La Defensa en la Política Exterior del Brasil: El Consejo Siramericano y la Estrategia Nacional de Defensa”. In Real Instituto Elcano, Documento de Trabajo 50 DT 50/2009 - 07/10/2009. In http://www.realinstitutoelcano.org/wps/portal/rielcano/ contenido?WCM_GLOBAL_CONTEXT=/elcano/elcano_es/zonas_es/america+latina/dt502009 (consultado em 17/06/2013) 2009c

. (2011) “'Defesa' ou 'Segurança’? Reflexôes em torno de Conceitos e Ideologias” in Contexto internacional, ISSN 0102.8529, PUC-Rio, junho/dezembro 2011 Vol 33, pp 407-435. 
SCHEETZ, Thomaz (2004) "Una evaluación del documento cepalino: 'Metodología estandarizada común para la medición de los gastos de defensa'”. Revista Fuerzas Armadas y Sociedad, Año 18, ํo 1-2, pp. 107-121.

SOARES, Luiz Felipe de Macedo (2004) “O Brasil no Cenário Regional de Defesa e Segurança”. Disponível em: http://www.defesa.gov.br/arquivos/colecao/brasil.pdf. Acesso realizado em 22/06/2012.

TORRES, Stephane (2011) "As Conferências de Ministros da Defesa das Américas: interesses brasileiros versus interesses norte-americanos.” Dissertação de Mestrado em Relações Internacionais - San Tiago Dantas (UNESP/UNICAMP/PUC-Sp), São Paulo. Disponível em: http:/www.santiagodantassp.locaweb.com.br/br/arquivos/defesas/sthefane_torres.pdf. Acesso realizado em 15/06/2012.

\section{Documentos oficiais (acessados entre junho e agosto de 2012)}

Livro Branco de Defesa Nacional do Brasil (LBDN- 2012): https://www.defesa.gov.br/ arquivos/2012/mes07/lbdn.pdf

Registro Sul-americano de gastos em defesa CEED-UNASUL: http://www.gedes.org.br/downlo ads/520ea114a42dd196326e02c61e275c1f.PDF

Acordos de bases militares Colômbia-EEUU: http://www.gedes.org.br/biblioteca.php?acao=exibi r\&tipo=download\&idcat $=19 \&$ pagina $=$ biblioteca\&criacao_de_sites=elisesb_pontocom

Livro Branco da Defesa Nacional - Brasil: http://www.defesa.gov.br/projetosweb/livrobranco/ orcamento_defesa.php

Criação do CEED: http://www.unasurcds.org/index.php?option=com_content\&view=article\& $\mathrm{id}=384 \% 3$ Aministro-de-defensa-del-peru-inaugura-centro-de-estudios-estrategicos-de-unasuren-buenos-aires\&catid=65\%3Anoticias-generales\&Itemid $=257 \&$ lang=pt

Metodologia CEPAL para gastos em Defesa Argentina e Chile: http:/www.eclac.cl/cgi-bin/ getProd.asp?xml=/prensa/noticias/comunicados/9/8699/P8699.xml\&xsl=/prensa/tpl/p6f. $\mathrm{xsl} \&$ base $=/$ prensa/tpl/top-bottom.xsl

\section{Reportagens e mídia online}

Reportagem Itamaraty sobre atuação da UNASUL em crises regionais. Disponível em: <http://www.itamaraty.gov.br/temas/america-do-sul-e-integracao-regional/unasul>. Acesso realizado em 6 de junho de 2013.

Reportagem Washington Post gastos em Defesa dos EUA. Disponível em: <http://www. washingtonpost.com/blogs/wonkblog/wp/2013/01/07/everything-chuck-hagel-needs-to-knowabout-the-defense-budget-in-charts/>. Acesso realizado em 1 de agosto de 2013.

Recebido em 8 de outubro de 2013

Aceito em 14 de março de 2014 


\title{
Resumo
}

Analisamos a metodologia de aferição de gastos em Defesa do Conselho de Defesa Sul-americano (CDS). Discutimos fundamentos, inovações, limitações e perfil de gastos. Na região, a folha de pagamento de pessoal e encargos previdenciários consumiram 60\% do total dos gastos em Defesa entre 2006 e 2010, enquanto as pesquisas em tecnologia apenas 0,5\%. Sobre esse diagnóstico, defendemos a modernização das FA e os Ministérios da Defesa da região, sobretudo uma racional e equalizada distribuição dos gastos por objeto, antes de aumentar as verbas para o setor.

Palavras-chave: Conselho de Defesa Sul-americano (CDS); Defesa; gastos em Defesa; medidas de confiança; segurança regional.

\begin{abstract}
We analyze the combined methodology developed by the South-American Defense Council (SDC) for assessing Defense expenditures. We examine its backgrounds, its limitations, its innovations and the profile of Defense budget expenditure. In this region, up to $60 \%$ of total Defense budget was allocated to personnel and their social security payroll; on the other hand, research and technology were allocated only $0.5 \%$. From the results, we defend the modernization of both Armed Forces and Defense Ministries in South America, specially a sensible equalization of their expenditure by subject, as a requisite for increasing the sector's budget.
\end{abstract}

Keywords: South American Defense Council (SDC); Defense; Defense expenditures; confidence measures; regional security. 